\title{
Article \\ Spoof Surface Plasmon Polaritons Developed from SIW Using Ring Slots and Vias
}

\author{
Longfei Tan ${ }^{1}$, Kaida $\mathrm{Xu}^{2, *(\mathbb{C})}$, Yiqun Liu ${ }^{2}$, Yingjiang Guo ${ }^{3}\left(\mathbb{D}\right.$ and Jianlei Cui ${ }^{4}$ \\ 1 Sichuan Fire Science and Technology Research Institute of Ministry of Emergency Management, \\ Chengdu 610036, China; tanlongfei@scfri.cn \\ 2 School of Information and Communications Engineering, Xi'an Jiaotong University, Xi'an 710049, China; \\ liuyiqunl@stu.xjtu.edu.cn \\ 3 Microsystem and Terahertz Research Center, China Academy of Engineering Physics, \\ Chengdu 610200,China; guoyingiiang_mtrc@caep.cn \\ 4 State Key Laboratory for Manufacturing Systems Engineering, Xi'an Jiaotong University, $\mathrm{Xi}^{\prime}$ an 710049, China; \\ cjlxjtu@mail.xjtu.edu.cn \\ * Correspondence: kaidaxu@ieee.org
}

Citation: Tan, L.; Xu, K.; Liu, Y.; Guo,

Y.; Cui, J. Spoof Surface Plasmon Polaritons Developed from SIW Using Ring Slots and Vias. Electronics 2021, 10, 1978. https://doi.org/ 10.3390/electronics10161978

Academic Editor: Massimo Donelli

Received: 20 July 2021

Accepted: 16 August 2021

Published: 17 August 2021

Publisher's Note: MDPI stays neutral with regard to jurisdictional claims in published maps and institutional affiliations.

Copyright: (c) 2021 by the authors. Licensee MDPI, Basel, Switzerland. This article is an open access article distributed under the terms and conditions of the Creative Commons Attribution (CC BY) license (https:// creativecommons.org/licenses/by/ $4.0 /)$.

\begin{abstract}
A new type of spoof surface plasmon polaritons (SSPPs) developed from conventional substrate integrated waveguide (SIW) using ring slots and vias is proposed in this paper. The asymptotic frequency and lower cutoff frequency of the SSPP structure can be easily tuned by changing the width of SIW walls and radius of the ring slot, respectively. A trapezoidal microstrip line and a small ring slot are used for the efficient mode conversion to smoothly transit from microstrip line to the proposed SSPP structure. The presented SSPPs have a flat bandpass filtering response with adjustable center frequency and bandwidth. In order to better verify the transmission and cutoff characteristics, two bandpass filters using the proposed SSPPs with relative bandwidths of $61.7 \%$ and $76.4 \%$, respectively, are fabricated and measured. Good agreement between the simulations and measurements verifies the proposed design idea.
\end{abstract}

Keywords: bandpass filter; ring slot; spoof surface plasmon polaritons; substrate integrated waveguide

\section{Introduction}

Surface plasmon polaritons (SPPs) are surface electromagnetic waves in the optical frequency band that propagate along the metal-dielectric interface but decay rapidly in the vertical direction [1]. In 2004, Pendry et al. proposed a periodic metal hole array that supports SPP-like surface mode having strong field confinement in the lower frequencies, which was named as designer or spoof SPPs [2]. Consequently, the theory and application of spoof SPPs (SSPPs) have been further explored at microwave and TeraHertz frequencies in recent years. Various planar ultra-thin SSPPs have been proposed for the design of bandpass filters (BPFs) [3-7], frequency splitters [8] and leaky wave antennas [9,10].

Compared with the traditional microwave filters, such as coupled line filters [11-14], waveguide filters [15-17], the SSPP based filters have the advantages of easily tunable bandwidth and fast design period through observing the dispersion characteristics of the SSPP unit cell, which are also a good candidate for the 5G or internet of thing applications [18]. However, the conventional ultra-thin SSPPs are generally constructed by corrugated strip lines, which are all open structures. Thus, the radiation loss and mutual coupling with other closely-spaced transmission lines or circuits are unavoidable. On the other hand, a balun has to be added if the traditional SSPP structures are applied in the BPF designs $[5,6]$ due to the intrinsic low-pass filtering characteristics of SSPPs $[19,20]$.

Substrate integrated waveguide (SIW) has been widely applied in the design of microwave circuits and antennas for its advantages of low loss, low profile, low crosstalk and so on [21-23]. In this paper, based on the traditional SIW, a new type of SSPP structure 
is proposed through loading ring slots and vias. The bandpass filtering response can be obtained with the help of SIW's high-pass characteristics, and the bandwidth can be easily tuned without increasing the size of the waveguide. Two BPFs using the proposed SSPPs with different bandwidths are fabricated and measured to validate the design idea.

\section{Analysis of SSPP Waveguide Developed from SIW}

The proposed SSPP structure based on SIW is shown in Figure 1, where the metal film has a thickness of $0.035 \mathrm{~mm}$ and is denoted in yellow. It consists of a conventional SIW with the periodic array of ring slots on the top metal layer and via holes. The via hole connected to the ground of the bottom metal layer is located at the center of the ring slot for each SSPP unit cell. The dielectric substrate sandwiched between the top and bottom metal layers is F4B using PTFE material from Wangling, which has a relative dielectric constant of 2.65, loss tangent of 0.0015 , and a thickness of $0.5 \mathrm{~mm}$. To further understand the properties of the proposed SSPP structure, its dispersion curves are analyzed. The parameters of the SSPP unit cell are set as follows: $w=8.2 \mathrm{~mm}, p=2.5 \mathrm{~mm}, g=0.85 \mathrm{~mm}$, $r=1 \mathrm{~mm}, s=0.15 \mathrm{~mm}, d_{\text {via_ } 1}=d_{\text {via_ } 2}=0.5 \mathrm{~mm}$.

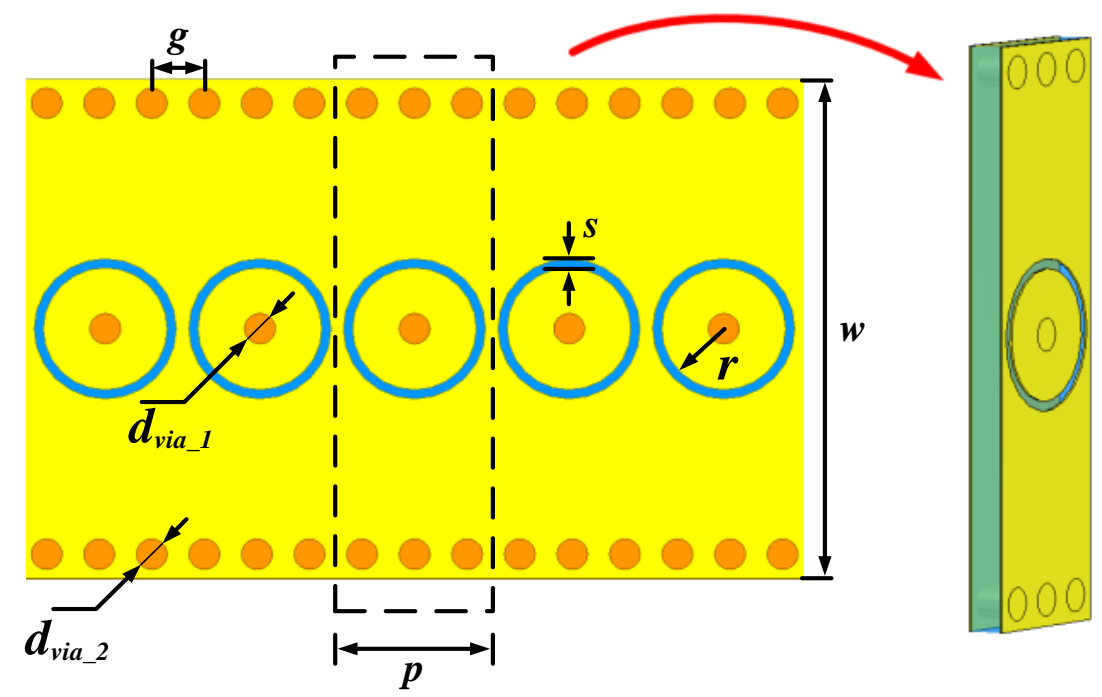

Figure 1. Schematic of the proposed SSPP structure.

The dispersion curves of the proposed SSPP structure with different values of parameters $w, r$, and $s$ are shown in Figure 2, where other parameters are maintained constantly. In Figure $2 \mathrm{a}$, as the radius of ring slot $r$ increases, the asymptotic frequency will be decreased, while the lower cutoff frequency remains essentially unchanged. It is indicated that the parameter $r$ mainly affects the cutoff frequency of the SSPP mode and has little effect on the cutoff frequency of the SIW. Additionally, as the SIW width $w$ increases while other parameters are kept unchanged, the lower cutoff frequency will be reduced as shown in Figure $2 b$. For the variation of parameter $s$ as illustrated in Figure $2 c$, both of the asymptotic frequency and lower cutoff frequency will be changed, which means that the dispersion of the proposed SSPP waveguide is sensitive to the width of the ring slot.

From the above analysis, it is observed that the proposed SSPP waveguide can be easily applied for the design of $\mathrm{BPF}$, and its left and right edges of the passband are mainly determined by the width of SIW walls and radius of the ring slot, respectively. Thus, the bandwidth and center frequency of the proposed SSPP developed from SIW can be easily manipulated by tuning the geometry dimensions of the SSPP unit cell. 

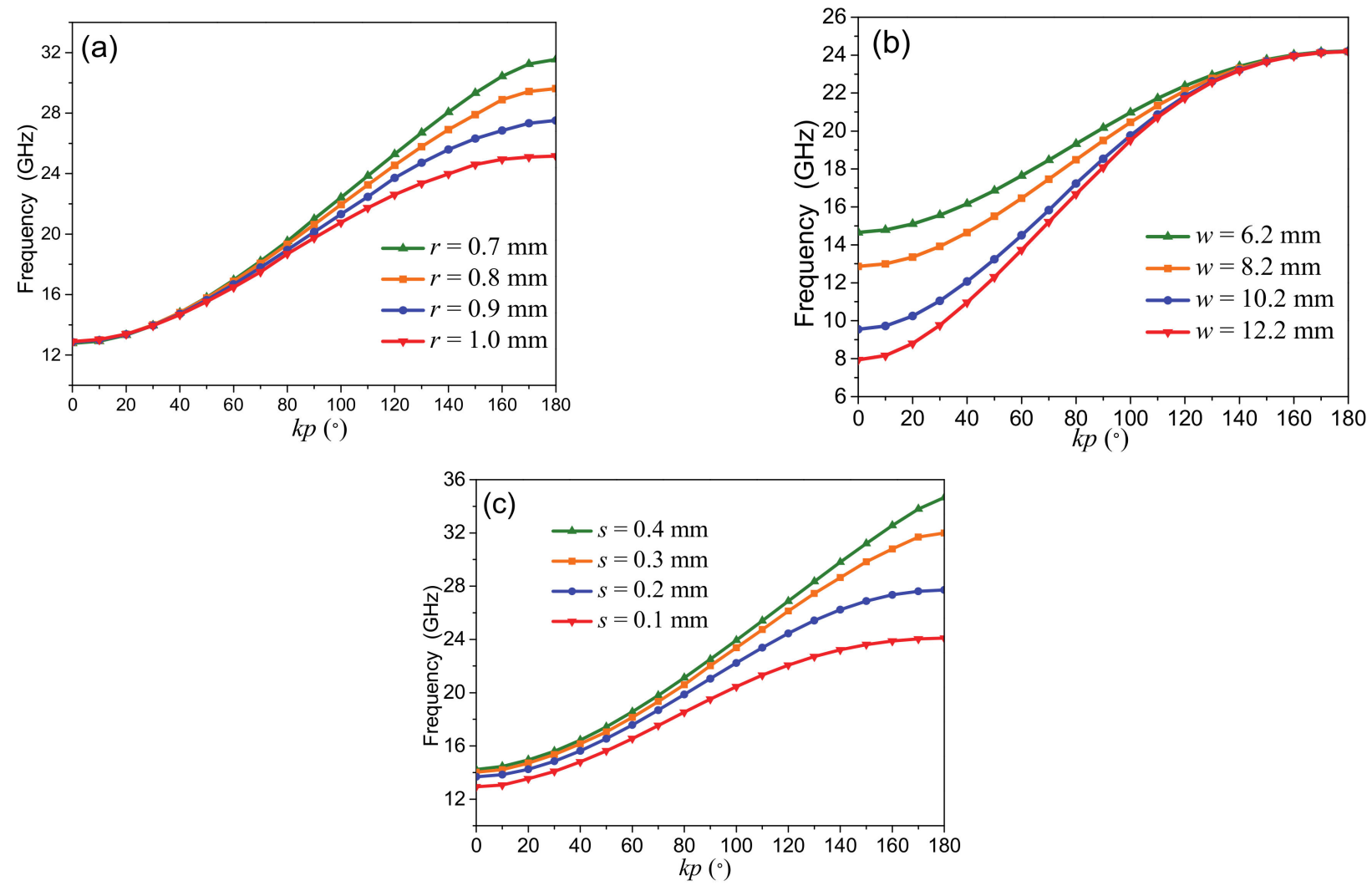

Figure 2. Dispersion curves of the proposed SSPP unit cell (a) with different $r$, (b) with different $w$, and (c) with different $s$.

\section{Design of Bandpass Filters Using the Proposed SSPPs}

On the basis of the dispersion characteristics of the SSPPs, a BPF using the proposed SSPP waveguide is designed. Figure 3 shows the schematic configuration of the BPF, which is composed of three parts: microstrip line as the input/output port connected with the SMA connector (up to $27 \mathrm{GHz}$ ) for facilitating the measurement, a transition part, and a periodic SSPP array structure with seven-unit cells. Since the existence of microstrip line is in order to feed the SSPP structure, the width of $w_{1}$ is set as $1.35 \mathrm{~mm}$ to realize the characteristic impedance of $50 \Omega$, for the impedance matching in RF circuit designs. Due to the momentum and impedance mismatchings between microstrip line and SSPPs, a simple transition part is necessary to be added by using a trapezoidal microstrip line and a smaller ring slot for the mode conversion. All detailed parameters are tabulated in Table 1.
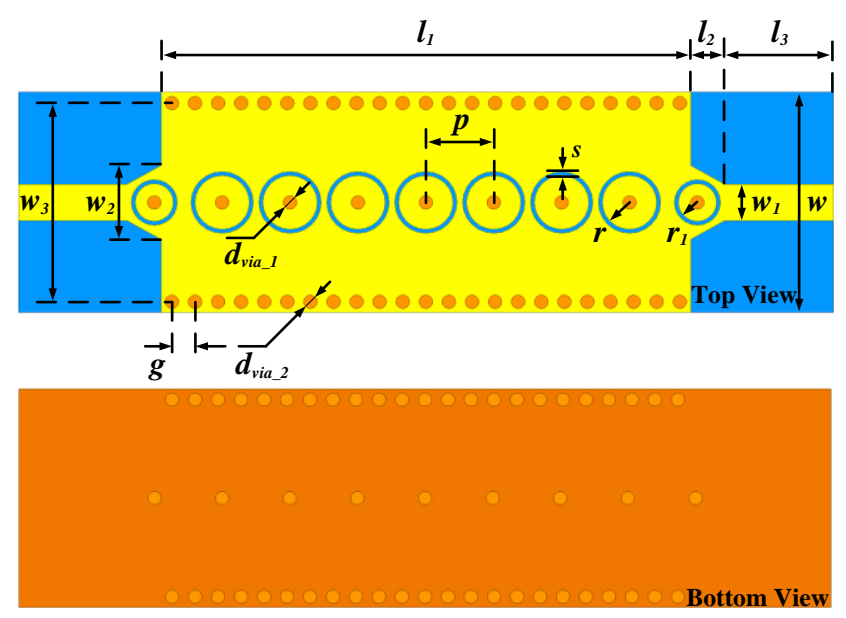

Figure 3. Schematic configuration of the BPF using the proposed SSPP. 
Table 1. Parameters of BPF Using the Proposed SSPP.

\begin{tabular}{cccccccc}
\hline Parameters & $w$ & $w_{\mathbf{1}}$ & $w_{\mathbf{2}}$ & $\boldsymbol{w}_{\mathbf{3}}$ & $\boldsymbol{r}$ & $\boldsymbol{r}_{\mathbf{1}}$ & $\boldsymbol{s}$ \\
\hline Values $(\mathrm{mm})$ & 8.2 & 1.35 & 2.75 & 7.4 & 1 & 0.7 & 0.15 \\
\hline Parameters & $g$ & $d_{\text {via_1 }}$ & $d_{\text {via_2 }}$ & $l_{1}$ & $l_{2}$ & $l_{3}$ & $p$ \\
\hline Values $(\mathrm{mm})$ & 0.85 & 0.5 & 0.5 & 19.5 & 1.25 & 4 & 2.5 \\
\hline
\end{tabular}

To further demonstrate the characteristics of the BPF using the proposed SSPP, a prototype example is fabricated as seen in Figure 4a with the identical dimensions in Table 1. Figure $4 \mathrm{~b}$ shows the simulation and measurement results of the $S$-parameters, where the left and right edges of the passband are at $13 \mathrm{GHz}$ and $24.6 \mathrm{GHz}$, respectively, basically consistent with the cutoff frequencies in Figure 2 for the parameters set in Table 1. Good agreement between the simulation and measurement can be observed. The center frequency is at $18.8 \mathrm{GHz}$ and the relative bandwidth is $61.7 \%$. It is speculated that using a dielectric substrate with lower loss tangent can improve the measured insertion losses.

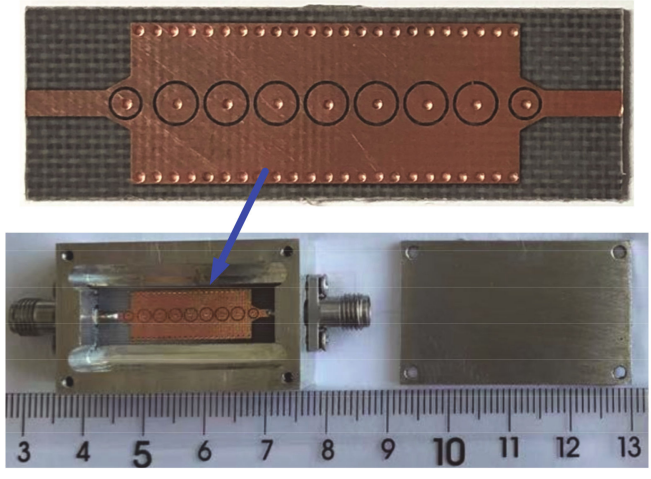

(a)

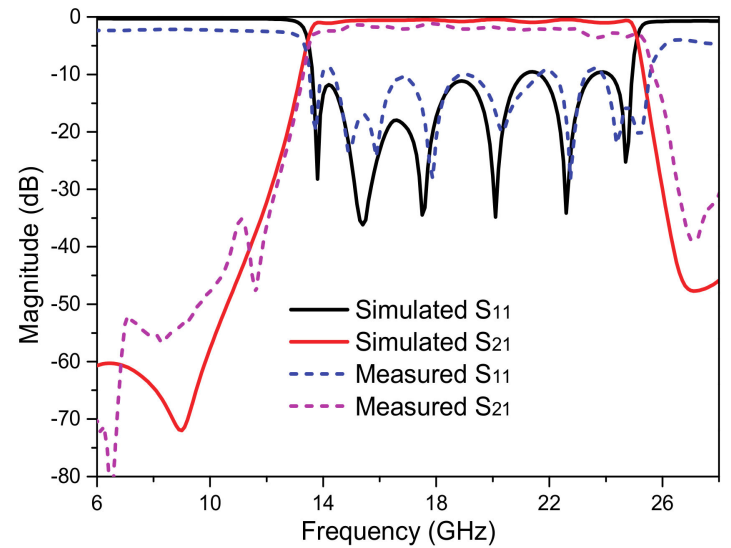

(b)

Figure 4. (a) Fabricated photograph of the BPF using SSPP and (b) the simulation and measurement of the BPF.

To validate the transmission characteristics of the proposed circuit, the electric field distributions at $20 \mathrm{GHz}$ and $7 \mathrm{GHz}$ are simulated by the commercial software CST Microwave Studio [24] as shown in Figure 5a,b, which are located within the passband and at the out-of-band, respectively. The electromagnetic signals can efficiently propagate from microstrip line to the proposed SSPP waveguide at $20 \mathrm{GHz}$ but are blocked quickly at the out-of-band, such as at $7 \mathrm{GHz}$.

As mentioned above, the left and right edges of the BPF's passband can be adjusted by the SIW and radius of the ring slot, respectively, thus the bandwidth and center frequency can be easily manipulated. Here, another SSPP unit cell example is designed with the lower cutoff frequency and asymptotic frequency at $11 \mathrm{GHz}$ and $24.6 \mathrm{GHz}$, respectively. The parameters $w_{3}=9 \mathrm{~mm}$ and $w=9.8 \mathrm{~mm}$ are set different from those of the first filter example while the other dimensions are the same. Figure 6 illustrates the dispersion characteristic comparisons between the two examples, where the asymptotic frequencies are the same at $24.6 \mathrm{GHz}$ since the cutoff frequency of the SSPP mode is not affected when the width of SIW wall is changed. For the lower cutoff frequency, it will be decreased from $13 \mathrm{GHz}$ to $11 \mathrm{GHz}$, thus the bandwidth will be broadened accordingly. The dash line shown in Figure 6 is the dispersion curve of the light line for reference to the two examples. 

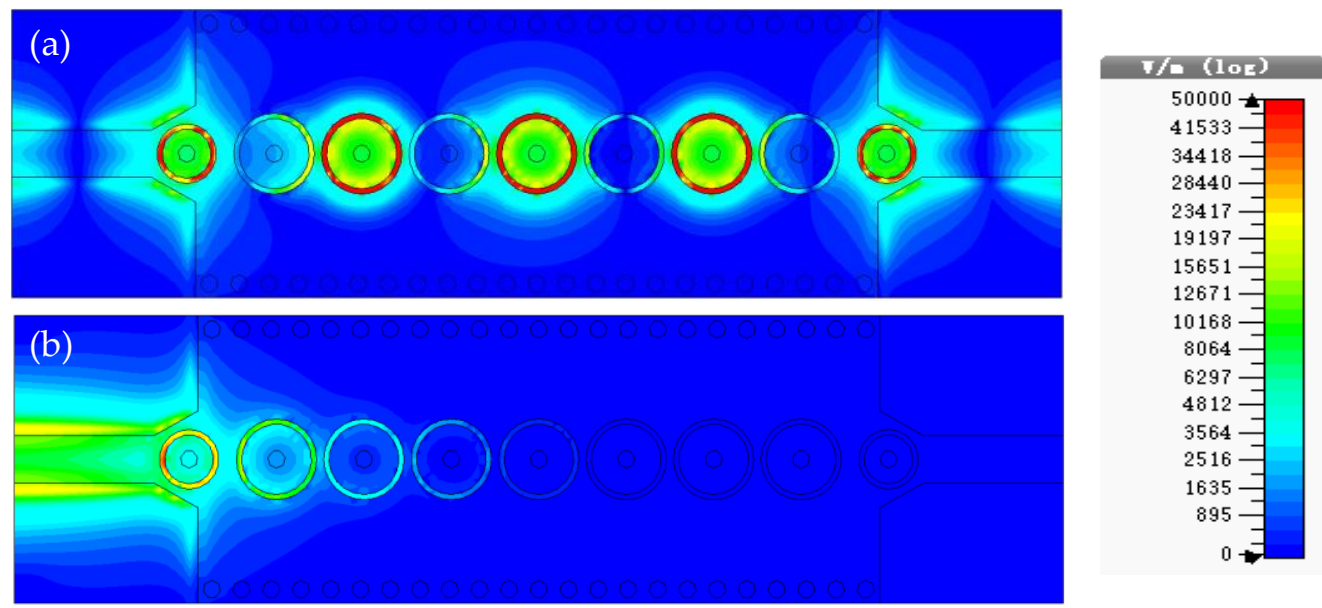

Figure 5. (a) Simulated electric field distributions of the BPF based on the proposed SSPP at $20 \mathrm{GHz}$. (b) Simulated electric field distributions at $7 \mathrm{GHz}$.

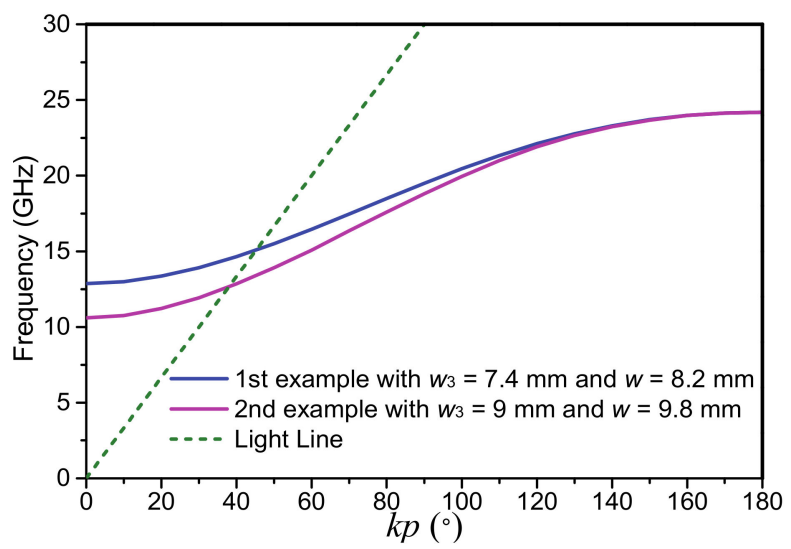

Figure 6. Dispersion characteristic comparisons between the SSPP unit cells with $w_{3}=7.4 \mathrm{~mm}$ and $w=8.2 \mathrm{~mm}$, and $w_{3}=9 \mathrm{~mm}$ and $w=9.8 \mathrm{~mm}$.

This BPF example based on the above-mentioned SSPP unit cell with the left and right edges of the passband at $11 \mathrm{GHz}$ and $24.6 \mathrm{GHz}$ is also fabricated and measured, as shown in Figure 7 . In addition to the difference of the width of SIW wall, the only difference from the first filter example in Table 1 is the parameters of the trapezoidal microstrip line in the transition part: $w_{2}=3.15 \mathrm{~mm}, l_{2}=2.25 \mathrm{~mm}$.

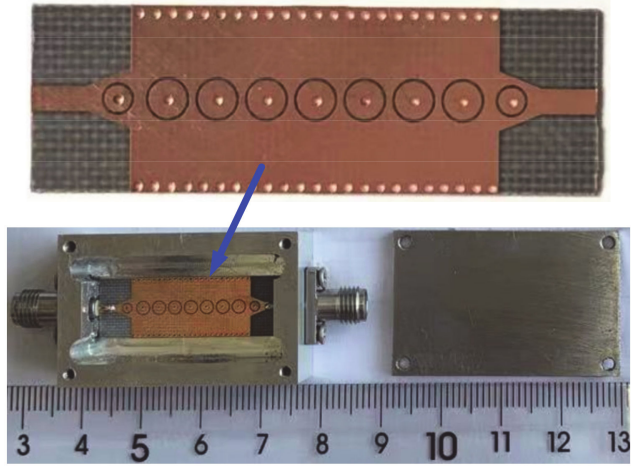

(a)

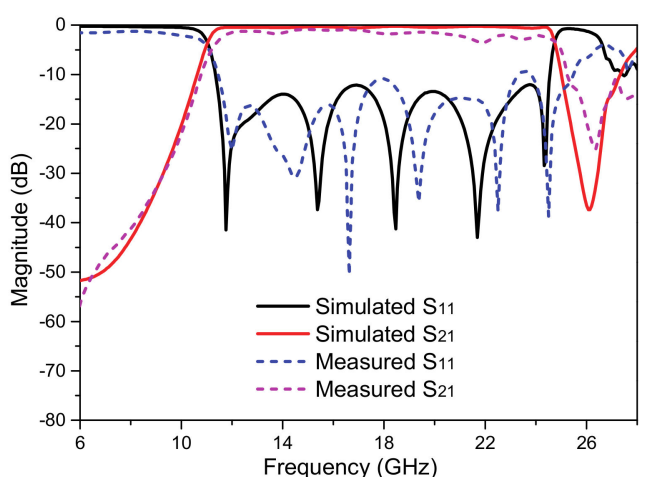

(b)

Figure 7. (a) Fabricated photograph of the second BPF example. (b) Its simulation and measurement results. 
Figure $7 \mathrm{a}$ is the fabricated photograph and Figure $7 \mathrm{~b}$ shows the comparisons between the simulation and measurement results, where they are in good agreement. It is observed that the left and right edges of the passband are at $11 \mathrm{GHz}$ and $24.6 \mathrm{GHz}$, respectively, consistent with the cutoff frequencies in Figure 6. The center frequency of this BPF is at $17.8 \mathrm{GHz}$ and the corresponding relative bandwidth is $76.4 \%$, which is wider than that of the first filter example.

In addition, the electric field distributions of the BPF with wider bandwidth at in-band frequency $20 \mathrm{GHz}$ and out-of-band frequency $7 \mathrm{GHz}$ are also demonstrated in Figure 8, which validates the transmission and cutoff characteristics of the proposed SSPP. Obviously, the electric fields at $7 \mathrm{GHz}$ suffer from strong suppression when propagating along the proposed structure. On the contrary, the electric fields at $20 \mathrm{GHz}$ can transmit from the input to output ports smoothly.

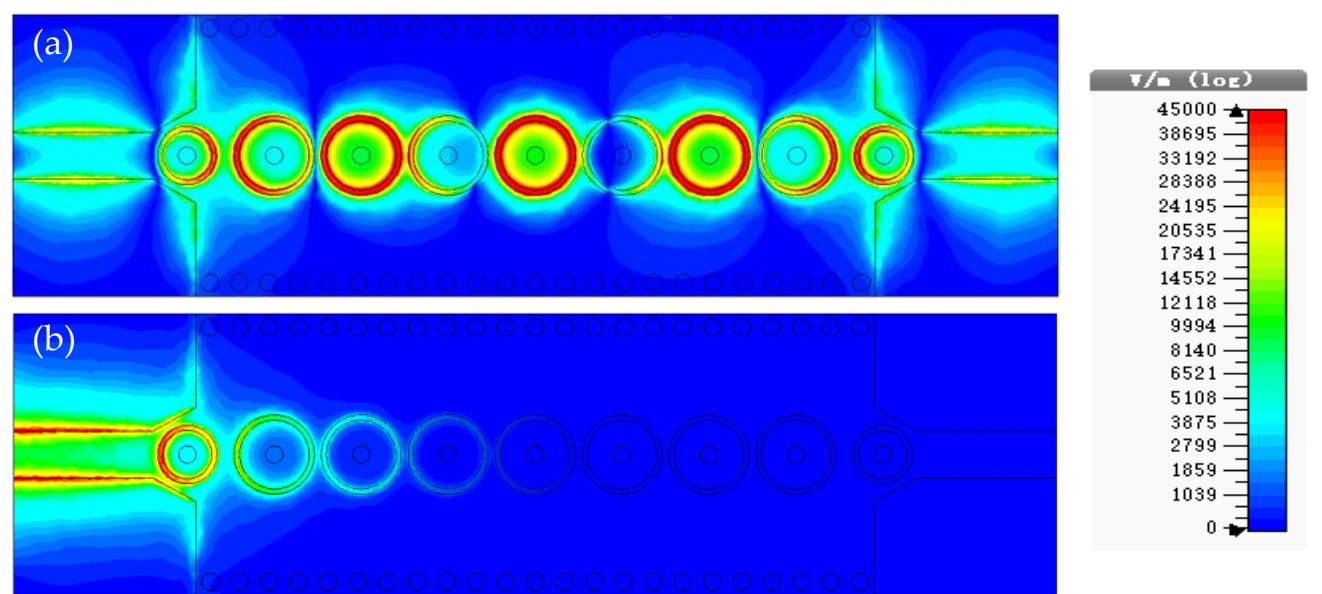

Figure 8. (a) Simulated electric field distributions of the second BPF example based on the proposed SSPP at $20 \mathrm{GHz}$. (b) Simulated electric field distributions at $7 \mathrm{GHz}$.

\section{Conclusions}

In this article, two BPFs based on the proposed SSPPs with good performance but different center frequencies and bandwidths have been presented. Combining with the SIW possessing high-pass property, the proposed SSPPs using ring slots and vias have been analyzed in detail and demonstrated experimentally. It is observed that the left and right edges of the BPF can be easily adjusted by changing the geometric parameters of the SSPPs, which will be of significant potential to the adaptive RF/terahertz front-end systems.

Author Contributions: Conceptualization, L.T. and K.X.; methodology, K.X.; software, L.T.; validation, L.T. and Y.L.; formal analysis, Y.L.; investigation, Y.G.; writing-original draft preparation, L.T. and K.X.; writing-review and editing, K.X.; supervision, K.X. and J.C. All authors have read and agreed to the published version of the manuscript.

Funding: This work was supported in part by the Scientific Research Projects of Fire Rescue Bureau of Emergency Management Department under Grant 2019XFGG11, in part by the Natural Science Foundation of Shaanxi Province under Grant 2021JQ-060, and in part by the "Siyuan Scholar" Fellowship of XJTU.

Institutional Review Board Statement: Not applicable.

Informed Consent Statement: Not applicable.

Data Availability Statement: The data presented in this study are available on request from the corresponding author.

Conflicts of Interest: The authors declare no conflict of interest. 


\section{References}

1. Barnes, W.L.; Dereux, A.; Ebbesen, T.W. Surface plasmon subwavelength optics. Nature 2003, 424, 824-830. [CrossRef]

2. Pendry, J.B.; Martín-Moreno, L.; Garcia-Vidal, F.J. Mimicking surface plasmons with structured surfaces. Science 2004, 305, 847-848. [CrossRef]

3. Xu, K.D.; Guo, Y.J.; Yang, Q.; Zhang, Y.L.; Deng, X.; Zhang, A.; Chen, Q. On-chip GaAs-based spoof surface plasmon polaritons at millimeter-wave regime. IEEE Photon. Technol. Lett. 2021, 33, 255-258. [CrossRef]

4. Zhao, L.; Zhang, X.; Wang, J.; Yu, W.H.; Li, J.D.; Su, H.; Shen, X.P. A novel broadband band-pass filter based on spoof surface plasmon polaritons. Sci. Rep. 2016, 6, 36069. [CrossRef] [PubMed]

5. Guo, Y.J.; Xu, K.D.; Liu, Y.H.; Tang, X.H. Novel surface plasmon polariton waveguides with enhanced field confinement for microwave-frequency ultra-wideband bandpass filters. IEEE Access 2018, 6, 10249-10256. [CrossRef]

6. Xu, K.D.; Zhang, F.; Guo, Y.; Ye, L.; Liu, Y. Spoof surface plasmon polaritons based on balanced coplanar stripline waveguides. IEEE Photon. Technol. Lett. 2020, 32, 55-58. [CrossRef]

7. Guo, Y.J.; Xu, K.D.; Deng, X.; Cheng, X.; Chen, Q. Millimeter-wave on-chip bandpass filter based on spoof surface plasmon polaritons. IEEE Electron Device Lett. 2020, 41, 1165-1168. [CrossRef]

8. Qi, C.; Liao, S.; Xue, Q. Frequency splitter based on spoof surface plasmon polariton transmission lines. Appl. Phys. Lett. 2018, 113, 161902. [CrossRef]

9. Kianinejad, A.; Chen, Z.N.; Qiu, C.W. A single-layered spoof-plasmon-mode leaky wave antenna with consistent gain. IEEE Trans. Antennas Propag. 2017, 65, 681-687. [CrossRef]

10. Zhang, X.F.; Fan, J.; Chen, J.X. High gain and high-efficiency millimeter-wave antenna based on spoof surface plasmon polaritons. IEEE Trans. Antennas Propag. 2019, 67, 687-691. [CrossRef]

11. Li, D.; Wang, J.A.; Liu, Y.; Chen, Z.; Yang, L. Compact quasi-elliptic bandpass filter with high selectivity using short-circuited coupled line. Microw. Opt. Technol. Lett. 2019, 61, 2873-2878. [CrossRef]

12. Alnahwi, F.M.; Al-Yasir, Y.I.A.; Abdulhameed, A.A.; Abdullah, A.S.; Abd-Alhameed, R.A. A Low-Cost Microwave Filter with Improved Passband and Stopband Characteristics Using Stub Loaded Multiple Mode Resonator for 5 G Mid-Band Applications. Electronics 2021, 10, 450. [CrossRef]

13. Li, D.; Xu, K.D. Multifunctional Switchable Filter Using Coupled-Line Structure. IEEE Microw. Wirel. Compon. Lett. 2021, 31, 457-460. [CrossRef]

14. La, D.S.; Guan, X.; Chen, S.M.; Li, Y.Y.; Guo, J.W. Wideband Band-Pass Filter Design Using Coupled Line Cross-Shaped Resonator. Electronics 2020, 9, 2173. [CrossRef]

15. Mrvić, M.; Potrebić, M.; Tošić, D. Compact E plane waveguide filter with multiple stopbands. Radio Sci. 2016, 51, 1895-1904. [CrossRef]

16. Zhao, P.; Wu, K. Waveguide Filters with Central-Post Resonators. IEEE Microw. Wirel. Compon. Lett. 2020, 30, 657-660. [CrossRef]

17. Tebeiro, F.; Arnedo, I.; Percaz, J.M.; Arrcgui, I.; Martin-Iglesias, P.; Lopetcgi, T.; Laso, M.A.G. Accurate Design Procedure for Waffle-Iron Low-Pass Filter. In Proceedings of the 2018 IEEE MTT-S International Microwave Symposium, Philadelphia, PA, USA, 10-15 June 2018.

18. Hilt, A. Availability and Fade Margin Calculations for 5G Microwave and Millimeter-Wave Anyhaul Links. Appl. Sci. 2019, 9 5240. [CrossRef]

19. Xu, K.D.; Guo, Y.J.; Deng, X.J. Terahertz broadband spoof surface plasmon polaritons using high-order mode developed from ultra-compact split-ring grooves. Opt. Express 2019, 27, 4354-4363. [CrossRef]

20. Li, J.; Shi, J.; Xu, K.D.; Guo, Y.J.; Zhang, A.; Chen, Q. Spoof surface plasmon polaritons developed from coplanar waveguides in microwave frequencies. IEEE Photon. Technol. Lett. 2020, 32, 1431-1434. [CrossRef]

21. Wang, Y.; Hong, W.; Dong, Y.; Liu, B.; Tang, H.J.; Chen, J.; Yin, X.; Wu, K. Half mode substrate integrated waveguide (HMSIW) bandpass filter. IEEE Microw. Wirel. Compon. Lett. 2007, 17, 265-267. [CrossRef]

22. Guan, D.; Peng, Y.; Zhang, Q.; Xiao, K.; Yong, S.-W. Hybrid Spoof Surface Plasmon Polariton and Substrate Integrated Waveguide Transmission Line and Its Application in Filter. IEEE Trans. Microw. Theory Tech. 2017, 65, 4925-4932. [CrossRef]

23. Li, W.; Xu, K.D.; Tang, X.; Yang, Y.; Liu, Y.; Liu, Q. Substrate integrated waveguide cavity-backed slot array antenna using high-order radiation modes for dual-band applications in K-band. IEEE Trans. Antennas Propag. 2017, 65, 4556-4565. [CrossRef]

24. CST Microwave Studio. CST Corp.: Darmstadt, Germany. Available online: www.cst.com (accessed on 1 August 2021). 